\title{
Em defesa da liberdade: as experiências de Lúcio José Maria de Souza na segunda metade do século XIX
}

\author{
Cristiane Santos de Jesus*
}

Resumo: Este artigo é uma versão adaptada de minha dissertação de mestrado que analisa a trajetória de Lúcio José Maria de Souza, um africano liberto que enfrenta a resistência das autoridades policiais baianas quando de seu desembarque no porto da cidade do Salvador, em 1871, após estada de onze meses na cidade de Lagos, Nigéria (África). Por meio da abordagem micro-histórica e do método indiciário de investigação analisam-se as estratégias e mecanismos utilizados por aquele africano em defesa de sua liberdade. Com isso, desejamos refletir sobre as experiências dos egressos da escravidão, em especial os africanos libertos, após a conquista da liberdade.

Palavras-chave: Lúcio José Maria de Souza; liberdade; século XIX.

Abstract: This article is an adapted version of my dissertation that analyzes the trajectory of Lúcio José Maria de Souza, an African freedman who faces resistance from the Bahian police authorities when he disembarked at the port of Salvador in 1871 after his stay of eleven months in the city of Lagos, Nigeria (Africa). Through the micro-historical approach and the indicial method of investigation, we analyze the strategies and mechanisms used by this African in defense of his freedom. With this, we wish to reflect on the experiences of the egress of slavery, especially freed Africans, after the conquest of freedom.

Keywords: Lúcio José Maria de Souza; freedom; XIX century.

\section{Introdução}

Lúcio José Maria de Souza era um africano liberto que fora escravizado na Bahia. Casado, com filho e afilhados residentes no Rio de Janeiro. O ano de

* Mestra em História Social pela Universidade Federal da Bahia (UFBA) com bolsa da Coordenação de Aperfeiçoamento de Pessoal de Nível Superior (CAPES). E-mail: cristiane.sdejesus@yahoo.com.br. 
sua chegada em Salvador permanece, por enquanto, desconhecido. Apesar de residir na Corte, ele viajou várias vezes para Salvador e desta cidade para Lagos. Conseguimos localizar pelo menos seis dessas viagens entre 1871 e 1885 . A primeira delas, em 1871, foi registrada na documentação policial por conta da apreensão que sofrera pela polícia do porto em Salvador. Naquela ocasião, aquele liberto africano foi impedido, pelas autoridades baianas, de desembarcar. Esse episódio é o ponto de partida deste artigo. Lúcio José é o personagem principal, mas outros sujeitos aparecem - uns mais, outros menos - ao longo da narrativa como integrantes de suas redes de convivência. Entre eles, sua esposa, a africana liberta, Benedita Rosa Leite; seu filho, João Lúcio; seus afilhados Lúcio e Luciana; o cônsul britânico, John Morgan e José Francisco de Oliveira, responsável por escrever a carta ao cônsul inglês. Aos poucos, sua história foi se esboçando na correspondência enviada ao cônsul inglês na Bahia, na carta de alforria, na certidão de casamento, nos registros de passaporte e em algumas correspondências da Secretaria de Segurança Pública do Rio de Janeiro.

A abordagem micro-histórica foi fundamental para a elaboração deste trabalho. Nascida dos debates historiográficos italianos da década de 1970, a micro-história consolidou-se nas décadas seguintes como campo de abordagem alternativo aos modelos explicativos marxista e funcionalista. Em sua gênese, estão as colaborações de Edoardo Grendi, Carlo Poni, Carlo Ginzburg, Giovanni Levi e outros. Segundo Henrique Espada, a micro-história foi resultado e reação à história social produzida tanto pela escola marxista inglesa quanto pelos Annales. ${ }^{1}$ Conforme esse autor, "os debates historiográficos italianos buscavam construir modelos explicativos mais adequados à convicção de que era possível, com o aperfeiçoamento dos métodos da história social, fortalecer a disciplina do ponto de vista científico." 2 Para Giovanni Levi, apesar da heterogeneidade natural da micro-história, ela caracteriza-se por:

Uma prática essencialmente baseada na redução da escala da observação, em uma análise microscópica e um estudo intensivo do material documental, o debate sobre o racionalismo, a pequena indicação como paradigma científico, o papel do particular, (não, entretanto, em oposição ao social), a atenção à narrativa, uma definição específica do contexto e a rejeição ao relativismo. ${ }^{3}$

Resguardadas as distinções naturais, a micro-história foi influenciada pela Antropologia, ao utilizar desta a descrição densa - que consiste na observação e descrição de indícios, sintomas e sinais inseridos em um contexto cultural. ${ }^{4}$ Desse diálogo, surgiu em uma das vertentes da micro-história, representada por Carlo Ginzburg, o paradigma indiciário. Este se caracteriza pela redução da escala de observação, valorização do objeto, dos detalhes, dos vestígios tomados como pistas, que ao serem interpretados, se inserem em um contexto social. Este artigo faz uso da micro-história - enquanto campo de abordagem -, e do paradigma indiciário, como procedimento metodológico. Por meio deles, analisam-se as estratégias e mecanismos utilizados por aquele africano em defesa de sua

LIMA, Henrique Espada. "Pensando as transformações e a recepção da micro-história nos debates de hoje". In: ALMEIDA, Carla Maria Carvalho de; OLIVEIRA, Mônica Ribeiro de. (Orgs). Exercícios de microhistória. Rio de Janeiro: FGV, 2009, p. 131-155.

2 LIMA. "Pensando as transformações e a recepção da micro-história nos debates de hoje", p. 136.

3 LEVI, Giovanni. "Sobre a micro-história". In: BURKE, Peter. (Org). A escrita da história: novas perspectivas. Tradução Magda Lopes. São Paulo: Editora da Unesp, p. 135-162.

4 GEERTZ, Clifford. A interpretação das culturas. Rio de Janeiro: LTC, 2008. 
liberdade. Com isso, pretendemos refletir sobre as experiências dos egressos da escravidão, em especial os africanos libertos, após a conquista da alforria.

Ao longo do texto, informações sobre a escravidão urbana no Brasil oitocentista dialogam com as experiências da vida na escravidão e em liberdade daquele africano. A narrativa, a organização do pensamento e os argumentos apresentados na carta enviada ao cônsul que intercedeu a seu favor foram analisados e interpretados de maneira a identificar os principais argumentos e demandas pela liberdade expressos por um africano em trânsito. A partir dessa abordagem, buscamos demonstrar que os significados da liberdade de Lúcio José eram representados pelo direito à livre locomoção, à estabilidade financeira e, sobretudo, pela manutenção dos laços e estabilidade familiar. Por fim, esperamos que este trabalho sirva para resgatar do anonimato a história desse protagonista, que tem nos ensinado um pouco mais sobre os limites e expectativas da liberdade de um alforriado africano no Brasil da segunda metade do século XIX.

\section{Entre Rio de Janeiro, Salvador e Lagos: as experiências de Lúcio José Maria de Souza}

O dia era 4 de abril de 1870. Lúcio José Maria de Souza foi à Secretaria de Polícia da Corte retirar seu passaporte. O roteiro da viagem já havia sido escolhido: Rio de Janeiro, Salvador e Lagos. Alguns dias depois, entre o final de abril e início de maio, ele ingressou em uma embarcação com destino à Cidade da Bahia. Em 19 de maio de 1870, com o passaporte vistoriado pela Secretaria de Polícia de Salvador, seguiu viagem para a cidade de Lagos. Até 1850, Lagos era uma das principais cidades envolvidas no comércio de africanos entre o Brasil e a costa ocidental da África. Ao se tornar protetorado e, posteriormente, colônia inglesa, ela se transformou em um dos principais destinos dos retornados, ex-escravos africanos e seus descendentes, que após conquistarem a alforria empreenderam viagens de retorno ao continente de origem.

Segundo Manuela Carneiro da Cunha, a década de 1830 marca o início das primeiras migrações de crioulos e africanos libertos do Brasil em direção à costa ocidental da África, popularmente conhecida como "costa dos escravos". ${ }^{5}$ Contudo, as migrações se intensificaram a partir da década de 1860 , tornando-se constantes durante as décadas de 1870, 1880 e 1890. Inúmeros fatores estão associados a essas migrações: o número crescente de alforriados no Brasil, o recrudescimento da repressão policial e o fortalecimento das comunidades de retornados no Golfo do Benim. Cidades como Lagos, Aguê e Uidá foram os principais destinos dos africanos que iniciaram a travessia em Salvador no oitocentos. ${ }^{6}$ Ao longo dos anos, as comunidades de retornados do Golfo do Benin passaram a ser conhecidas como agudás, brésilliens ou retornados.

Pesquisadores como Lorenzo Dow Turner, Pierre Verger, Manuela Carneiro da Cunha, Elisée Soumonni, Kristin Mann e Milton Gurán concluíram que essas comunidades se construíram socialmente a partir dos contatos com o Brasil.?

5 CUNHA, Manuela Carneiro da. Negros estrangeiros - os escravos africanos e sua volta à África. $2^{\mathrm{a}}$ ed. São Paulo: Companhia das Letras, 2012.

6 A migração dos africanos e descendentes para a costa ocidental da África é discutida mais amplamente no segundo capítulo de minha dissertação.

7 Sobre isso ver: VERGER, Pierre. Fluxo e refluxo de tráfico de escravos entre o Golfo do Benim e a Baía de Todos os Santos - dos séculos XVII ao XIX. $3^{\text {a }}$. ed. Tradução: Tasso Gadzanis. São Paulo: Corrupio, 1987; 
"As trocas deram-se nas duas direções, e cada um dos lados do Atlântico não era de todo desconhecido e indiferente, de modo que o que se passava na África atlântica repercutia no Brasil e vice-versa", segundo Alberto da Costa e Silva. ${ }^{8}$ De acordo com Pierre Verger, havia 1.237 e 2.732 retornados do Brasil em Lagos em 1871 e 1881 , respectivamente. ${ }^{9}$ Essa comunidade era constituída por portugueses e brasileiros - comerciantes de escravos - mulatos, capitães de navios negreiros e africanos libertos retornados do Brasil. ${ }^{10}$ Durante a década de 1870 , houve um fluxo e refluxo - parafraseando Verger - intenso de africanos libertos e crioulos livres, oriundos tanto de Salvador, Recife, Rio Grande do Sul, quanto do Rio de Janeiro em direção às cidades litorâneas de Lagos e Ajudá. A pesquisadora Lisa Castillo apresenta informações relevantes sobre o fluxo de pessoas nos sentidos Lagos-Salvador entre as décadas de 1870 e 1880:

[...] embora as viagens dos ex-escravos à África sejam frequentemente concebidas como uma única e definitiva travessia do Atlântico, no sentido oeste-leste, os registros de passageiros que entraram e saíram do porto da Bahia na segunda metade do século XIX deixam claro que muitos dos viajantes que foram à África voltaram a Salvador. Algumas pessoas o faziam várias vezes. Para alguns, Lagos seria o lugar de moradia permanente e as viagens ao Brasil eram apenas visitas curtas. Outros [...] continuavam a morar na Bahia indo a Lagos por período limitado."

Em sua tese de doutoramento, Mônica Lima analisou o movimento de retorno à África dos libertos africanos a partir dos portos das cidades do Salvador e Rio de Janeiro. O retorno a partir do Rio de Janeiro tinha como destino principal as cidades da região Congo-Angola. No entanto, a autora constatou que, semelhantemente a Salvador, houve, na década de 1870, o crescimento no número de africanos libertos que saíam daquela cidade em direção à Costa Ocidental da África. ${ }^{12}$. Nina Rodrigues testemunhou, no porto de Salvador, um dos últimos embarques de africanos do século XIX. Num dos trechos mais citados do seu relato, ele comentou sobre o momento de embarque dos passageiros marcado por,

[...] profunda emoção, que assisti em 1897 uma turma de velhos Nagôs e Haussás, já bem perto do termo da existência, muitos de passo incerto e cobertos de alvas cãs tão seródias na sua raça, atravessar a cidade em alvoroço, a embarcar para a África, em busca da paz do túmulo nas mesmas plagas em que tiveram o berço. Dolorosa impressão a daquela gente, estrangeira no seio do povo que a vira envelhecer curvada ao cativeiro e que agora, tão alheio e intrigado diante da ruidosa satisfação dos inválidos que se iam, como da recolhida tristeza dos que ficavam, assistia, indiferente ou possuído de efêmera curiosidade, àquele emocionante espetáculo da restituição aos penates dos despojos de uma raça destroçada pela escravidão. ${ }^{13}$

CUNHA, Manuela Carneiro da. Negros estrangeiros - os escravos africanos e sua volta à África. $2^{\mathrm{a}}$ ed. São Paulo: Companhia das Letras, 2012; SOUMONNI, Elisée. Daomé e o mundo Atlântico. Amsterdã/Rio de Janeiro: SEPHIS/CEAO, 2001, p. 5-18; GURAN, Milton. Agudás: os brasileiros do Benim. Rio de Janeiro: Nova Fronteira, 2000.

8 SILVA, Alberto da Costa e. "O Brasil, a África e o Atlântico no século XIX”. Estudos Avançados, São Paulo, v. 8 n. 21, 1994, p. 22.

9 VERGER. Fluxo e refluxo de tráfico de escravos entre o Golfo do Benim e a Baía de Todos os Santos, p. 622.

10 VERGER. Fluxo e refluxo de tráfico de escravos entre o Golfo do Benim e a Baía de Todos os Santos, p. 602.

11 CASTILLO, Lisa Earl; PARÉS, Nicolau. "Marcelina da Silva e seu mundo: novos dados para uma historiografia do candomblé ketu". Afro-Ásia, Salvador, n. 36, 2007, p. 113.

12 LIMA e SOUZA, Mônica. "Entre margens: o retorno à África de libertos no Brasil, 1830-1870" (Tese de doutorado em História, Universidade Federal Fluminense, 2008), p. 121.

13 RODRIGUES, Raimundo Nina. Os africanos no Brasil. São Paulo: Nacional, 1977, p. 107. 
O vai e vem de libertos entre Rio de Janeiro, Salvador e Lagos era alimentado por africanos e crioulos que buscavam reencontrar parentes no continente africano ou se inseriam nas redes comerciais e religiosas que alimentavam o intercâmbio mercantil e religioso nas duas margens do Atlântico. De modo geral, os autores Pierre Verger, Manuela Carneiro da Cunha, João Reis, Nicolau Parés e Lisa Castillo concordam que esse trânsito foi fundamental para a constituição de práticas religiosas, a exemplo do candomblé. ${ }^{14} \mathrm{O}$ comércio entre Brasil - incluindo Rio de Janeiro e Pernambuco - e a cidade de Lagos era feito, principalmente, através do porto de Salvador. Panos da costa, noz de cola, sabão, azeite de palma, azeite de dendê, esteiras, contas, cabaças, búzios, tambores eram os principais itens que alimentavam o comércio entre Brasil e África. Nicolau Parés sinaliza que "todos esses produtos são importantes objetos rituais no candomblé, e o seu comércio continuado indicaria o valor e a eficácia religiosa atribuída pelos praticantes à sua origem africana". ${ }^{15}$ Além das questões religiosas, a participação de africanos libertos em atividades comerciais desse tipo pode ser, conforme Gabriela Sampaio, o resultado de escolhas em que,

a opção pela continuidade das viagens e do trabalho com o comércio de produtos africanos se mostrou interessante para esses africanos que se engajaram na continuidade do que faziam quando ainda eram escravos. Esta deve ter sido a forma não só de sobreviver, mas também de acumular dinheiro e bens, apesar das dificuldades que enfrentavam como estrangeiros. Mas a opção por esta atividade talvez, não fosse só pelas vantagens econômicas. [...] talvez, então, as relações estabelecidas nas viagens trouxeram algum prestígio para esses africanos libertos. ${ }^{16}$

Não encontramos informações sobre a embarcação que transportou Lúcio José a Lagos, mas é sabido que ele retornou a Salvador no patacho Eugênio, em março de 1871. A referida embarcação era propriedade do português Francisco de Almeida Rebello, e realizava a travessia entre o litoral brasileiro e a costa ocidental do continente africano na segunda metade do século XIX. Sob o comando do capitão José Fernandes Talhada, o Eugênio atravessou pelo menos seis vezes o Atlântico: em setembro de 1870; março de 1871; novembro de 1872; 1873; 1874 e abril de $1877 .{ }^{17}$ Lúcio José não era um criminoso, não havia mandados de prisão contra ele e nem era procurado pela Justiça, mas, após a inspeção da polícia do porto, foi impedido de desembarcar e permanecer na cidade do Salvador em março de 1871. Esse impedimento atendia às exigências da lei de 7 de novembro de 1831.

Fruto do acordo internacional entre Brasil e Inglaterra, assinado em 1826, a Lei Feijó, como ficou conhecida, foi o primeiro instrumento legal elaborado e aprovado no Império brasileiro cujo objetivo era acabar com o comércio de africanos para o Brasil. Composta por nove artigos, tal lei proibia o ingresso no país de qualquer escravo de fora do território nacional; definia como importadores

14 VERGER. Fluxo e refluxo de tráfico de escravos entre o Golfo do Benim e a Baía de Todos os Santos; CUNHA. Negros estrangeiros; REIS, João José. Domingos Sodré, um sacerdote africano: escravidão, liberdade e candomblé na Bahia do século XIX. São Paulo: Companhia das Letras, 2008; CASTILLO, Lisa Earl. "Entre memória, mito e história: viajantes transatlânticos da Casa Branca". In: AZEVEDO, Elciene; REIS, João. (Org.). Escravidão e suas sombras. Salvador: Edufba, 2012, p. 93-94.

15 PARĖS, Nicolau. "Mundo atlântico e constituição da hegemonia nagô no candomblé baiano". Revista Esboços, Florianópolis, v. 17, n. 23, 2010, p. 176.

16 SAMPAIO, Gabriela. "Africanos em trânsito entre Salvador e Rio de Janeiro nas últimas décadas do século XIX". In: SOUZA, Evergton; RAGGI, Giuseppina; CARDIM, Pedro (orgs). Salvador da Bahia - Retratos de uma sociedade atlântica (séculos XVII- XIX). Salvador: EDUFBA; Lisboa: CHAM, 2015.

17 APEB, Seção Colonial, Livros de entrada de passageiros, v. 2 e 3, 1873-1883. 
ilegais de escravos, mestres, contramestres, compradores e qualquer pessoa que, conscientemente, abrigasse ou colaborasse com o desembarque de escravos importados ilegalmente. As penas para crimes dessa natureza iam desde o castigo físico até o pagamento de multas. Isso estimulou a denúncia sobre desembarques ilegais de escravos e estabeleceu o pagamento de trinta mil réis como prêmio a ser pago ao denunciante. Nesse contexto, a retenção e o impedimento sofridos por Lúcio José no verão de 1871 encontraram fundamento no artigo Art. $7^{\circ}$, segundo o qual, "não será permitido a qualquer homem liberto, que não for brasileiro, desembarcar nos portos do Brasil debaixo de qualquer motivo que seja. O que desembarcar será imediatamente reexportado".

Os argumentos apresentados por Lúcio José ao chefe de polícia baiano não surtiram efeito, pelo menos de imediato, e ele continuou impedido de retornar ao Rio de Janeiro. Ao capitão do Eugênio, José Fernandes Talhada, atendendo à normativa da lei de 7 de novembro de 1831, coube a obrigação de pagar a multa de cem réis por ter trazido o dito africano para o Brasil. Após o pagamento da multa, o chefe de polícia permitiu que Lúcio José permanecesse na cidade do Salvador até que houvesse navio que o reexportasse à África. Na verdade, o próprio Eugênio ficou impedido de regressar à costa africana, uma vez que a intenção do chefe de polícia era de fazer Lúcio José retornar a Lagos naquela embarcação.

Vasta é a bibliografia especializada no estudo dessa lei. Entre os principais autores, encontramos as obras de Beatriz Mamigonian, Tâmis Parron, Elciene Azevedo e mais recentemente Sidney Chalhoub. ${ }^{18}$ A força da escravidão, escrito por Chalhoub, traz a ideia do revigoramento da escravidão ou "segundo escravismo", estimulado pela não aplicação da lei de 1831. Na perspectiva do autor, o ressurgimento, por outro lado, tornou precária a experiência de liberdade de africanos livres, libertos, pessoas negras pobres e seus descendentes no Brasil oitocentista. Tal precarização era representada pelo não reconhecimento do direito à liberdade plena dos africanos livres - termo usado para classificar todos os africanos importados ilegalmente para o Brasil-, o risco iminente da reescravização de libertos, associada à revogação das alforrias condicionais e/ou à escravização de pessoas livres de cor. ${ }^{19} \mathrm{~A}$ experiência de Lúcio José na Bahia em 1871 é aqui compreendida como um exemplo de liberdade precária, não em relação a seu status jurídico, e sim, em relação às condições instáveis de acesso à "cidadania", uma vez que a experiência vivida por aquele africano no porto de Salvador demonstrou as restrições impostas aos direitos de liberdade dos africanos. Apesar das restrições ora expostas, aplicadas aos africanos libertos, veremos mais adiante que Lúcio José tinha plenos conhecimentos sobre a necessidade de estabelecer vínculos com pessoas em condições de protegê-lo. Exemplo disso foi o pedido de assistência feito ao cônsul britânico, John Morgan, residente em Salvador.

18 MAMIGONIAN, Beatriz Galloti. "O direito de ser africano livre: os escravos e as interpretações da lei de 1831". In: LARA, S. H; MENDONÇA, Joseli (Org). Direitos e justiças no Brasil: ensaios de história social. Campinas: Editora da Unicamp, 2006, p. 129-160; PARRON, Tâmis. A política da escravidão no Império do Brasil, 1826-1865. Rio de Janeiro: Civilização Brasileira, 2011; AZEVEDO, Elciene. O direito dos escravos: lutas jurídicas e abolicionismo na Província de São Paulo: Campinas: Editora da Unicamp, 2010.

19 CHALHOUB, Sidney. A força da escravidão - ilegalidade e costume no Brasil oitocentista. São Paulo: Companhia das Letras, 2012. 


\section{Escravos, africanos libertos e as restrições legais no Império do Brasil}

Alvo constante de suspeição, os africanos sofriam restrições legais mais intensas, facilitadas por sua condição de apátridas. ${ }^{20}$ A Constituição de 1824 estabelecia os cidadãos brasileiros: todos os nascidos no Brasil; os estrangeiros naturalizados; os portugueses que aderiram ao projeto da independência e os filhos de brasileiros nascidos no exterior. ${ }^{21}$ Os escravos naturais do país, crioulos, eram cidadãos somente após a conquista da alforria. Apesar de restrita, esse tipo de cidadania lhes garantia o direito de votar nas eleições primárias; participar da Guarda Nacional, exceto como oficial; podiam constituir família livremente; fazer contratos e possuir bens. ${ }^{22}$ Contudo, há um completo silêncio em relação à cidadania dos africanos libertos. Ao estudar as legislações das décadas de 1830-1840 aplicadas aos africanos escravizados e forros na Bahia, Luciana Brito evidenciou que os projetos constitutivos de tais leis percebiam o africano como um "estrangeiro que atrapalhava as propostas de construção de uma nação brasileira, tanto em termos políticos quanto culturais". 23

A associação entre o silêncio constitucional sobre a cidadania dos africanos libertos e as legislações criadas para controlá-los, ampliava, segundo Luciana Brito, entre os africanos, as precárias condições de liberdade. ${ }^{24} \mathrm{Em}$ trabalho publicado recentemente, Luciana Brito analisou as legislações nacional e baiana aplicadas aos africanos libertos, elaboradas nas décadas de 1830 e 1840, cujos objetivos incluíam, controlar os espaços de trabalho, restringir a circulação e limitar a liberdade dos africanos libertos. A elaboração dessas restrições e das demais, aprovadas após o Levante Malê de 1835, fundamentavam-se no "medo branco" em relação à natureza subversiva do africano. Desse modo, as leis e posturas criadas nas décadas de $1830,1840,1850$ e 1860 se inserem no projeto de dificultar a vida em liberdade dos forros, em particular, os africanos. Além de Luciana Brito, Manuela Carneiro da Cunha, João Reis e Sidney Chalhoub são alguns pesquisadores que examinaram as legislações restritivas aplicadas aos africanos libertos a partir da segunda metade do século XIX.

A primeira delas foi o decreto provincial de 14 de dezembro de 1830, que restringia e controlava a circulação dos escravos e a liberdade dos africanos libertos, pois definia que nem um nem outro poderiam circular sem a apresentação de documentação específica. No caso do escravo, era obrigatória a apresentação de uma cédula concedida pelo senhor com as seguintes informações: nomes do cativo e do proprietário, local de moradia e destino. Ao africano, por sua vez, cabia apresentar o passaporte concedido pelo juiz criminal ou de paz. Semelhante a esse decreto, o Código de Processo do Império do Brasil, aprovado em 1832, determinava que escravos acompanhados por seus senhores e libertos deveriam sempre portar passaportes em suas viagens. ${ }^{25}$

20 CUNHA. "Negros Estrangeiros", 95.

21 MAMIGONIAN, Beatriz, Galloti. "O direito dos libertos africanos no Brasil oitocentista: entre razões do direito e considerações finais". História, São Paulo, v. 34, n. 2, p. 181-205, jul./dez. 2015.

22 BRITO, Luciana da Cruz. Temores da África - segurança, legislação e população africana na Bahia oitocentista. Salvador: Editora da UFBA, 2016, p. 40.

23 BRITO. Temores da África, p. 40.

24 CHALHOUB, Sidney. "Precariedade estrutural: o problema da liberdade no Brasil escravista (século XIX)". História Social, Campinas, n. 19, 2010, p. 23.

25 BRITO. Temores da África, p. 56. 
Analisada sobretudo por João Reis e Luciana Brito, a Lei nº 9, de 13 de Maio de 1835, fora criada como resposta à Revolta dos Malês, episódio intensamente analisado por Reis. ${ }^{26} \mathrm{~A}$ referida lei impedia que os africanos libertos possuíssem bens de raiz; incentivava a delação de insurreições; premiava o delator com a isenção do pagamentos de taxas obrigatórias; regulamentava a deportação de africanos suspeitos de subversão; ampliava o controle sobre o local de trabalho e alimentava a subordinação do africano liberto a seu empregador; além de controlar os espaços de moradia africana, uma vez que casas ou espaços de trabalhos só poderiam ser alugados mediante autorização de um juiz. ${ }^{27} \mathrm{Em}$ relação à legislação municipal da cidade do Salvador, Reis evidencia a existência da Postura n. ${ }^{\circ} 68$, de 1859, que:

punia com uma multa de mil réis ou, alternativamente, quatro dias de prisão, o escravo africano encontrado na rua à noite sem bilhete assinado pelo senhor ou pela senhora, em que se declare para onde vai, o seu nome e lugar de moradia; a mesma postura penalizava com multa de 3 mil réis, ou oito dias de prisão, os africanos libertos encontrados nas ruas às mesmas horas, que não levarem bilhete de qualquer cidadão brasileiro. ${ }^{28}$

O comércio de rua e o transporte de mercadorias, atividades praticadas tanto por escravos, libertos e algumas pessoas livres, também foi alvo do controle das autoridades imperiais. Todo liberto que atuasse vendendo em caixinhas, tabuleiros, gamelas, trabalhasse carregando cadeiras de arruar ou remassem fora do porto deviam pagar o imposto provincial anual de 10 mil réis. João Reis esclarece que em 1856 esse imposto foi alterado para 20 mil réis. Nesse mesmo período, todo africano liberto que desejasse exercer qualquer ofício mecânico, era obrigado a pagar outro imposto no valor de 10 mil réis. Segundo Reis, "a ideia era expulsar os africanos, além do comércio, do ramo dos ofícios, da artesania, enfim, da pequena produção independente, reservando apenas o serviço da lavoura como ocupação opcional". 29

Consciente das restrições legais impostas aos africanos, escravos ou forros, com o direito de circulação mais restringido pelo chefe de polícia e o risco de retorno iminente a Lagos, Lúcio José Maria de Souza buscou proteção junto ao consulado britânico instalado em Salvador. Em 10 de abril de 1871, o africano narrou sua história para José Francisco de Oliveira. Ainda não encontramos informações sobre ele, nem sobre o tipo de relação mantida com o africano, mas o que ficou claro na análise da documentação é que José Francisco de Oliveira não só foi o responsável pela redação da carta enviada ao cônsul britânico, como pode também ter sido seu emissário. Analisando a comunicação de John Morgan com autoridades brasileiras, nota-se que há muitos anos ele estava no exercício daquele cargo, mantendo extensa correspondência com a Presidência da província entre as décadas de 1850 e 1880 sobre os mais variados assuntos. ${ }^{30}$

A pertinência do pedido de ajuda ao cônsul inglês pode ser explicada pelo fato de Lúcio José ter regressado ao Brasil portando dois passaportes: o primeiro

26 REIS, João José. Rebelião escrava no Brasil - a história do levante dos malês em 1835. São Paulo: Companhia das Letras, 2003.

27 REIS. Rebelião escrava no Brasil, p. 421-544.

28 REIS. Domingos Sodré, um sacerdote africano, p. 88.

29 REIS. Domingos Sodré, um sacerdote africano, p. 90.

30 ALBUQUERQUE, Wlamyra Ribeiro. O jogo da dissimulação - abolição e cidadania negra no Brasil. São Paulo: Companhia das Letras, 2009, p. 45-93. 
expedido pela Secretaria de Polícia do Rio de Janeiro e visado pela Secretaria de Polícia de Salvador no ano de 1870; o segundo adquirido na cidade de Lagos, concedido pelo cônsul britânico John. H. Glover, ali residente. Ao analisar o movimento de retorno de libertos em Lagos e a instalação dos saros em Serra Leoa, Pierre Verger revelou que, em 1858, o cônsul inglês Benjamin Campbell, residente em Lagos, distribuía passaportes ingleses aos africanos libertos que desejassem retornar ao interior do continente; esses documentos foram emitidos em inglês e mais tarde impressos em árabe. ${ }^{31}$

Seis anos após o caso Lúcio José, em agosto de 1877, a assistência do cônsul John Morgan foi novamente solicitada por dezesseis passageiros do patacho Paraguassu. Eramafricanoslibertos, possuidores de passaportes ingleses, impedidos de desembarcar e permanecer em Salvador com base na lei de 7 de novembro de 1831. Em O jogo da dissimulação, Wlamyra Albuquerque analisou exaustivamente o episódio, possibilitando ao leitor acompanhar, por meio da atuação do cônsul, a dinâmica das relações diplomáticas e econômicas entre Brasil e Inglaterra. ${ }^{32}$ Ao ter conhecimento do impedimento sofrido pelos dezesseis africanos, John Morgan solicitou "explicações ao presidente da província, enfatizando que os implicados eram súditos de cor preta de S. M. Britânica, autorizados a viajar pelo governo de Lagos". 33 De acordo com Albuquerque, o cônsul afirmou conhecer a proibição do ingresso de africanos libertos no Brasil, porém alegou ser aquela situação diferente, pois mesmo tendo nascido na costa da África, aqueles passageiros faziam parte do território do Império britânico. Para Albuquerque, "tal ressalva só reforçava a tutela inglesa. Ou seja, apesar de africanos, eram súditos ingleses e como tais deveriam ser tratados". 34

Diferentemente da história de Lúcio José, o caso dos africanos do Paraguassu foi amplamente discutido no Conselho de Estado - órgão consultivo e deliberativo, cuja função era assistir o imperador. À sombra do caso Paraguassu, e das experiências vividas por J. A. Cole, imigrante norte-americano cuja companheira, uma mulher negra, livre, foi impedida de ingressar no Brasil, Albuquerque assinala que "essas trajetórias convergiram para o mesmo ponto: como evitar que pessoas de cor imigrassem para o Brasil sem lançar mão de uma legislação racista?" O fio de Ariadne foi compreender o processo de racialização das relações sociais em construção no Brasil durante as últimas décadas de século XIX. Para ela, "na perspectiva racial, a resistência governamental remetia a um projeto social excludente, que estava em gestação no contexto de desarticulação da escravidão". ${ }^{55}$ Apesar da intervenção de John Morgan, a decisão do Conselho de Estado foi unânime: os dezesseis africano deviam retornar a Lagos.

Na carta escrita em 10 de abril de 1871, Lucio José Maria de Souza se identificou como africano liberto, mina, casado, com filho menor nascido neste país e com domicílio não interrompido na Freguesia de Santa Rita, na Corte. Claudio Honorato considera que as freguesias cariocas de Santa Rita e Sacramento concentravam o maior número de moradias populares no século XIX..$^{36} \mathrm{Em} 1870$, a freguesia de Santa Rita ocupava, no Rio de Janeiro, o segundo lugar de freguesia carioca de maior população com 23.810 moradores, antecedida apenas pela freguesia de Santana

31 VERGER. Fluxo e refluxo de tráfico de escravos entre o Golfo do Benim e a Baía de Todos os Santos, p. 617.

32 ALBUQUERQUE. O jogo da dissimulação, p. 45-93.

33 ALBUQUERQUE. O jogo da dissimulação, p. 64.

34 ALBUQUERQUE. O jogo da dissimulação, p. 64.

35 ALBUQUERQUE. O jogo da dissimulação, p. 67.

36 HONORATO, Claudio de Paula. "Valongo: o mercado de escravos do Rio de Janeiro, 1758-183" (Dissertação de mestrado em História, Universidade Federal Fluminense, 2008), p. 41. 
com 35.686 habitantes. ${ }^{37}$ Essas freguesias eram espaços nos quais a interação entre negros, mulatos, africanos, livres, libertos e brancos ocorria cotidianamente. "Enfim, moradias escravas e negras igualmente redefiniam as cidades atlânticas e produziam novos territórios", é o que afirma Carlos Araújo ao analisar a importância das moradias cariocas para a construção de redes de sociabilidade negras. ${ }^{38}$ Esses locais poderiam ser o resultado de escolhas pessoais que visavam construir ou fortalecer laços de solidariedade. Lúcio José e sua esposa podem ter sido movidos por esses fatores quando fixaram residência na Travessa da Conceição, $n^{\circ}$ 10, na freguesia de Santa Rita. De acordo com Araújo,

\begin{abstract}
os africanos libertos efetivamente faziam escolhas sociais e culturais para seus locais de moradia. Tudo indica que nesse período [18601900] - e possivelmente até antes - forros africanos tendiam a morar juntos, em comunidades densas, em que laços de companheirismo e mesmo de parentesco de nação - como citado por Cortês de Oliveira agregavam indivíduos em busca de segurança, proteção e apoio diário de sobrevivência. ${ }^{39}$
\end{abstract}

Para o liberto, era imprescindível firmar laços por dentro da classe senhorial, pois ele não escapava das relações paternalistas tecidas no mundo da escravidão. Ao recorrer à assistência do cônsul, Lúcio José evidenciou a importância de relações paternalistas como essa na luta cotidiana para a manutenção da liberdade. Por enquanto, são poucas as informações sobre sua vida como escravo na Bahia, mas de acordo com dados apresentados na certidão de casamento, Lúcio José foi "exposto aos santos óleos" em uma das igrejas localizada na freguesia da Penha, uma das dez freguesias urbanas de Salvador. Segundo Ana Amélia Nascimento, essa freguesia era formada por uma expressiva população livre e branca. No censo de $1855,87,93 \%$ da população da Penha era constituída por pessoas livres, 3,49\% por libertos e $8,58 \%$ por escravos..$^{40}$ Quando questionado pelo chefe de polícia sobre sua vinda a Salvador, em maio de 1870 e março de 1871, Lúcio José afirmou que tirara seu passaporte para a Bahia porque desejava ver a terra onde havia passado longo período de sua vida em cativeiro. É possível que, na condição de escravo, ele tenha transitado nas ruas de Salvador entre as freguesias da Penha, Pilar, Conceição, Carmo e Sé, provavelmente, carregando mercadorias de um lado a outro, vendendo ou prestando serviços a terceiros como escravo de ganho.

Como escravo em Salvador, Lúcio José criou vínculos com outros escravos, libertos e pessoas livres, o que não impediu que fosse vendido para a Corte, por conta do tráfico interprovincial. A data exata e o processo de migração forçada para a cidade do Rio de Janeiro permanecem, por enquanto, desconhecidos, mas é possível que as experiências adquiridas nos anos como escravo urbano em Salvador tenham-no ajudado a adaptar-se à Corte. Em 1861, aos quarenta anos de idade, ele comprou sua alforria pelo valor de um conto e seiscentos mil réis. Manolo Florentino evidencia que na cidade do Rio de Janeiro os africanos estiveram à frente dos crioulos quando o assunto era a aquisição da alforria:

37 HONORATO. "Valongo", p. 41.

38 ARAUJO, Carlos Eduardo Moreira... [et al.]. Cidades Negras: africanos, crioulos e espaços urbanos no Brasil escravista do século XIX. $2^{a}$ ed. São Paulo: Alameda, 2006, p. 83.

39 FARIAS, Juliana Barreto; GOMES, Flavio dos Santos; SOARES, Carlos Eugênio Líbano. No labirinto das nações: africanos e identidades no Rio de Janeiro, século XIX. Rio de Janeiro: Arquivo Nacional, 2005, p. 184.

40 NASCIMENTO, Anna Amélia. Dez freguesias da cidade do Salvador: aspectos sociais e urbanos do século XIX. Salvador: Fundação Cultural do Estado da Bahia, 1986, p. 90-92. 
Os africanos representavam de $52 \%$ a $55 \%$ dos escravos que conseguiam ultrapassar o cativeiro nos anos 40 e 50. Foram necessários mais de dez anos após o final do comércio negreiro para que eles se vissem definitivamente suplantados pelos crioulos na corrida rumo à liberdade. E mesmo assim continuaram a alcançar a expressiva cifra de $45 \%$ de todos os que lograram obter cartas de alforria no período $1860-1864 .{ }^{41}$

Já para a Bahia, Kátia Mattoso chegou à conclusão de que a transição entre a década de 1850 e 1860 marcou o ápice do preço das alforrias na província baiana. Esse crescimento estaria relacionado à demanda europeia por itens produzidos por meio da mão de obra escrava, associado ao fim do tráfico de africanos para o Brasil. Tais fatores teriam contribuído com a elevação dos preços dos cativos. Em 3 de janeiro de 1863, o preto forro e mina Lúcio José Maria de Souza recebeu em matrimônio a africana liberta, mina, Benedita Rosa Leite. Assim como o cônjuge, Benedita era africana liberta e foi escravizada na Bahia. Seus tempos de escravidão em Salvador foram vividos na freguesia do Pilar. Enquanto a freguesia da Penha estava localizada nos limites urbanos de Salvador, a do Pilar se localizava no centro comercial e portuário da cidade. De acordo com Nascimento, o Pilar era o lugar onde muitos comerciantes viviam, devido à proximidade do porto. Ricos comerciantes e traficantes de escravos, portugueses e brasileiros residiam ali. ${ }^{42}$ Para Mary Karasch, "a busca da estabilidade familiar era provavelmente a força mais potente por trás da busca pela liberdade, talvez um símbolo para eles de que suas famílias não poderiam ser mais vendidas". ${ }^{43}$

Se as uniões entre libertos significavam o apoio e a estabilidade garantidos pelo casamento legalizado, para os africanos o casamento era ainda mais emblemático por causa de sua condição de estrangeiros pois eles "encontravam na sociedade conjugal um mínimo de apoio no presente e segurança no futuro, além da solidariedade étnico-cultural como sugere a constatada endogamia", assinala Maria Inês Côrtes. ${ }^{44}$ Essa endogamia não era exclusiva dos africanos escravizados na Bahia. Ao investigar os registros de casamento da freguesia de Sacramento, no Rio de Janeiro, entre as décadas de 1830 e 1860, Juliana Farias chegou à conclusão de que nesse período a endogamia era mais frequente entre africanos minas e nagôs do que entre os centro-ocidentais e orientais. A autora afirma que

\footnotetext{
Mesmo com a pequena oferta de pretendentes na Corte, homens e mulheres minas - e também seus descendentes - preferiam desposar parceiros de sua nação. Ao menos na freguesia de Sacramento. Ainda que não estivessem "fechados" a outros grupos, eles tendiam a se organizar neste e em outros mercados da cidade, como o do trabalho ou liberdade, e também nas irmandades católicas e nos espaços sociais de lazer. 45
}

A necessidade de auxílio mútuo não exclui a importância da afetividade entre os cônjuges pois ela poderia estimular o surgimento de redes de sociabilidades que ultrapassavam o núcleo familiar, a exemplo das relações de compadrio. Situação,

41 FLORENTINO, Manolo. "Alforrias e etnicidade no Rio de Janeiro oitocentista: notas de pesquisa". Topoi. Revista de História, Rio de Janeiro, v. 5, p. 14, 2002.

42 NASCIMENTO. Dez freguesias da cidade do Salvador, p. 90-92.

43 KARASCH, Mary. C. A vida dos escravos no Rio de Janeiro (1808-1850). Tradução de Pedro Maia Soares. São Paulo: Companhia das Letras, 2000, p. 474.

44 OLIVEIRA, Maria Inês Côrtes de. O liberto: seu mundo e os outros. São Paulo: Corrupio, 1988, p. 60.

45 FARIAS; Juliana Barreto. "Mercados Minas: africanos ocidentais na Praça do Mercado do Rio de Janeiro 1830-1890" (Tese de doutorado em História, Universidade de São Paulo, 2012), p. 196. 
aliás, vivida por Lúcio José e Benedita Rosa, que na efervescência das ruas e morros da freguesia de Santa Rita, criavam e educavam três crianças - o filho João Lúcio, e os afilhados Lúcio e Luciana, os quais criavam e educavam regularmente. Sobre os vínculos de compadrio, Côrtes evidencia que,

\begin{abstract}
a utilização de formas de parentesco ritual foi uma das soluções encontradas pelos africanos ao longo de seu processo de ressocialização para substituir os vínculos familiares desfeitos com o cativeiro. Paralelamente às irmandades religiosas e às famílias-de-santo organizadas nas comunidades dos terreiros, os africanos valeramse também do compadrio como mais uma instituição destinada a fortalecer os laços que os ligavam aos membros de sua comunidade e tecer uma rede de proteção e apoio para os seus filhos. ${ }^{46}$
\end{abstract}

Os vínculos da relação de compadrio estabeleciam entre compadres, padrinhos e afilhados direitos e obrigações de amparo e prestação de serviços mútuos. Escravos e libertos significaram a instituição do compadrio, atribuindo-lhe importância fundamental no processo de construção e ampliação dos espaços de convivência. Lúcio e Benedita eram africanos, tinham sido escravizados na Bahia e no Rio de Janeiro eram identificados como "mina". "Mina" era um termo usado na capital do Império para identificar os africanos embarcados durante o comércio de escravos nos portos de Uidá, Pequeno Popó, Grande Popó, Porto Novo, Badagri e Lagos, localizados no atual Golfo do Benim, costa ocidental do continente africano. Na Bahia, eram conhecidos como nagôs. Flávio Gomes e Carlos Soares afirmam que a palavra mina seria um guarda-chuva étnico, capaz de acoplar identidades étnicas múltiplas, reconstruídas a partir das experiências da vida em cativeiro e em liberdade. ${ }^{47}$ Eles acreditam que as redes de comunicação e convivência dos minas podem ter alcançado o outro lado do Atlântico, a partir da circulação desses africanos libertos entre o Brasil e o litoral, podendo ter contribuído com a reconfiguração de identidades étnicas. ${ }^{48}$

Viagens de libertos africanos e seus descendentes para a África e o retorno para o Brasil não seriam incomuns. Em várias regiões africanas, as identidades - e posteriormente argumentos diacríticos de "nacionalismo" étnicos - acabariam sendo refeitas com ingredientes das experiências de libertos que retornavam. Este movimento de realinhamentos identitários de ex-escravos que retornaram para a África nos ajuda a entender as possíveis construções simbólicas e agenciamentos de identidades de africanos nas experiências da escravidão e liberdade no Brasil. Talvez seguindo estas pistas poderemos vislumbrar tradições transétnicas e étnicas de reconfigurações de identidades africanas crioulas, escravas e livres. Os africanos minas formariam assim, comunidades intra-atlânticas e transatlânticas. ${ }^{49}$

Sobre a reorganização de identidades, Gabriela Sampaio chama atenção para a necessidade de considerar o peso do tráfico interprovincial entre 1850-1888, uma vez que o crescimento da circulação de indivíduos foi relevante para o processo

46 OLIVEIRA, Maria Inês Côrtes de. "Viver e morrer no meio dos seus: nações e comunidades africanas na Bahia do século XIX". Revista USP, São Paulo, n. 28, p. 18-94, dez/-fev. 1996.

47 GOMES, Flávio; SOARES, Carlos Eugênio Líbano. "Com o pé sobre o vulcão - africanos minas, identidades e repressão antiafricana no Rio de Janeiro (1830-1840)". Estudos Afro-Asiáticos, n. 2, 2001, p. 39.

48 GOMES; SOARES. "Com o pé sobre o vulcão", p. 39.

49 GOMES; SOARES. "Com o pé sobre o vulcão", p. 34. 
de reconfiguração identitária. ${ }^{50}$ Tal crescimento teria gerado disputas em torno dos espaços de moradia e trabalho, além de ter contribuído com a organização de redes de sociabilidades. Segundo Sampaio,

o número de sujeitos em circulação aumenta muito quando levamos em conta as migrações relacionadas ao tráfico interprovincial. Isto é, com a venda e partida forçada de escravos para o sul, muitos libertos e livres que faziam parte das redes de relações desses escravos também partiram para outras províncias, neste caso voluntariamente, tentando recuperar o contato com entes queridos. ${ }^{51}$

Conforme Juliana Farias, a adesão à identidade mina possibilitava a inserção dos nagôsnas redes construídas no Rio de Janeiro desde o século XVIII, organizandose em áreas de trabalho, lazer, práticas religiosas e moradia. ${ }^{52}$ Segundo ela, "tornarse mina não significava despojar-se parcial ou completamente de seu passado nagô na Bahia ou em outros lugares. As experiências de outrora eram revividas ou adaptadas na vida diária e nas atividades que realizavam em casa e nas ruas". ${ }^{33}$ No mercado do trabalho no Rio de Janeiro, dois espaços eram ocupados pelos minas: o comércio de rua e as atividades de ganho. ${ }^{54} \mathrm{Em}$ suas bancas, vendiam legumes, verduras, frutas, peixes. De acordo com Farias, "ao deixarem seus lugares por falecimento ou desistência dos negócios, esses africanos eram logo substituídos por parceiros e cônjuges da mesma procedência". 55

Apesar de dispersa e cheia de lacunas, a documentação sobre Lúcio José apresenta indícios de sua inserção no comércio de rua da Corte, amplamente dominado pelos minas. Os principais indícios que fundamentam essa hipótese são um registro de matrícula e o envio do jovem escravo Antônio, comprado em Salvador por Lúcio José e enviado à cidade do Rio de Janeiro em setembro de $1873 .{ }^{56}$ Sobre as atividades comerciais dos minas com outras províncias brasileiras, Farias assinala que "há evidências do fluxo e refluxo regulares de pequenos negociantes minas-nagôs entre Rio, Bahia e Pernambuco, envolvendo comércio de joias, panos, objetos de cultos aos orixás e também escravos". ${ }^{57} \mathrm{O}$ segundo vestígio diz respeito aos fragmentos da carta escrita ao cônsul John Morgan, nos quais o africano faz referências aos "seus pequenos haveres, adquiridos com perseverante indústria, com economia, com probidade, sob a proteção das leis e autoridades". ${ }^{8}$

\section{A defesa de Lúcio José Maria de Souza}

A liberdade era, portanto, como bem definiu Eric Foner, "um terreno de conflitos que poderia ter significados diferentes tanto para negros como para

\footnotetext{
50 SAMPAIO, Gabriela dos Reis. "Conexões Rio-Bahia: Identidades e dinâmica cultural entre trabalhadores, 1850-1888". Revista Acervo, Rio de Janeiro, v. 22, n. 1, jan./jun. 2009, p. 73.

51 SAMPAIO. "Conexões Rio-Bahia", p. 70.

52 FARIAS. "Mercados Minas", p. 49.

53 FARIAS. "Mercados Minas", p. 49.

54 O mercado de rua era amplamente dominado pelas africanas minas. Sobre isso ver: FARIA, Sheila de Castro. "Damas e mercadoras: as pretas minas no Rio de Janeiro (século XVIII-1850)". In: SOARES, Mariza de Carvalho (Org). Rotas atlânticas da diáspora africana: na Baía do Benim ao Rio de Janeiro. Niterói: Editora da UFF, 2007, p. 101-134.

55 FARIAS. "Mercados Minas", p. 147.

56 APEB, Seção Colonial/Provincial, Pedidos de Passaportes, Maço 5903, Período: 1873-1874.

57 FARIAS. "Mercados Minas", p. 159.

58 APEB, Seção Colonial/ Provincial, Correspondências do Consulado Inglês, Maço 1193, 1872-1879.
} 
brancos". ${ }^{59} \mathrm{~A}$ carta escrita ao cônsul John Morgan exaltava a obediência, o trabalho, o patriotismo e, sobretudo, a questão familiar do suplicante. Destacaremos alguns argumentos presentes na missiva que compõem a defesa daquele africano. $O$ primeiro diz respeito à sua natureza inofensiva e laboriosa porque

[...] a todo o ente humano sendo facultada a residência neste Império dela querem privar o suplicante inofensivo que outra pátria não tem senão o mesmo Império onde parte no cativeiro parte no gozo de sua liberdade envelheceu aumentando com o produto do seu trabalho a fortuna pública $[\ldots]^{60}$

Enquanto a aparente deferência é o principal mecanismo que articula sua defesa, há nesse processo um jogo entre subordinação e argumentação. $O$ tom subserviente adquire ao longo das linhas posicionamento político, à medida que são expostas as justificativas que compõem a defesa do africano. Recorrer à natureza inofensiva e laboriosa de Lúcio José foi uma estratégia usada para afastar dele qualquer imagem de perigo que era associada naquela época aos libertos, especialmente os africanos. O segundo argumento apresentado na carta reforça seu compromisso com o trabalho: "[...] por que na Corte, onde é domiciliário, tem seus pequenos haveres adquiridos com perseverante indústria, com economia, com probidade, sob a proteção das leis e autoridades [...]." Reforçar seu compromisso com o trabalho e com a manutenção da ordem fortalecia a ideia de que ele não trazia perigos à sociedade e ao projeto de manutenção da ordem social empreendido pelo Estado imperial, cujos princípios, analisados anteriormente, fundamentavam-se nas legislações que regiam a manutenção da segurança e o controle da mão de obra.

A terceira premissa diz respeito ao patriotismo ou à ideia de pertencimento sobre os quais Lúcio José buscou afastar de si qualquer vínculo com costumes e práticas consideradas africanas "[...] porque, sem recursos para uma volta à África onde ninguém o conhece, onde nada possui, cujos costumes lhe são estranhos, o obrigam a ir ali viver ou antes morrer na miséria, longe de tudo quanto possui, de tudo quanto conhece, de tudo quanto ama [...]". ${ }^{62} \mathrm{~A}$ exposição do casamento religioso foi outra tática utilizada para fortalecer sua obediência aos padrões e ao estilo de vida considerados ideais. Para Karasch, o casamento religioso era utilizado como instrumento que buscava a respeitabilidade e a integração na sociedade carioca, além de ser um instrumento de distinção social ao diferenciar o "status social especial do liberto". ${ }^{63}$

Outro argumento presente na carta é o uso recorrente da imagem do filho, João Lúcio. Tal argumento reforça o apelo à questão familiar. João Lúcio nascera livre, como tal estava suscetível a dispor de direitos civis e políticos, desde que atendesse às prerrogativas impostas na Constituição. Como africanos libertos, Lúcio José Maria de Souza e sua esposa, Benedita Rosa Leite de Souza, estavam às margens da sociedade brasileira, mas o filho, João Lúcio, além de ter nascido livre, era brasileiro, e como tal, cidadão.

59 FONER, Eric. "O significado da liberdade". Revista Brasileira de História, n. 16, v. 8, 1988, p. 9.

60 APEB, Seção Colonial/Provincial, Correspondências do Consulado Inglês, Maço 1193, 1872-1879.

61 APEB, Seção Colonial/ Provincial, Correspondências do Consulado Inglês, Maço 1193, 1872-1879.

62 APEB, Seção Colonial/ Provincial, Correspondências do Consulado Inglês, Maço 1193, 1872-1879.

63 KARASCH. A vida dos escravos no Rio de Janeiro, p. 475. 
[...] enfim, porque tal expatriação ofende aos próprios laços de sangue, privando-se um filho Brasileiro, menor, da natural proteção de seu pai e condenando-o sem causa legítima à mais odiosa e injustificável orfandade, não resultante da morte do progenitor de seus dias, mas da separação eterna a que em vida o querem condenar [...] pode no Império vigorar decreto que ao africano liberto feche as portas do Brasil e dele o repila? Ainda mesmo que aí têm mulheres, filhos, interesses, sem que em outra parte possa achar uma pátria? [...] seja feita justiça ao suplicante, a sua mulher, a seu filho, que como Brasileiro tem direito ser atendido quando pede muito e muito pouco, isto é que não o privem de seu pai. ${ }^{64}$

A alusão constante à figura de João Lúcio serviu para manter o equilíbrio entre a nacionalidade estrangeira de seu pai e demais africanos que, a contragosto, vieram para o Brasil; e a condição de cidadão brasileiro do filho. É a esta distinção de cidadão brasileiro que o autor da carta recorre, tendo em vista que naquele período, 1871, a população nacional era formada em grande parte por descendentes de africanos, muitos dos quais nascidos livres como o próprio João Lúcio.

A linha argumentativa que sustenta a defesa de Lúcio José converge para as discussões sobre os direitos dos africanos libertos no Brasil oitocentista apresentados por Beatriz Mamigonian. Vimos que a Constituição de 1824 manteve os africanos libertos no "limbo" - expressão utilizada por Mamigonian para se referir à condição de apátridas daqueles. Marcado por divergências, o projeto constitucional de 1823 dividia-se, a grosso modo, entre a exclusão completa ou a inserção restrita dos libertos africanos no rol de cidadãos brasileiros. O parecer final do Conselho de Estado optou pela exclusão completa dos africanos libertos. Contudo, a noção de cidadania defendida por Lúcio José na comunicação enviada ao cônsul transparece ideias e argumentos defendidos por alguns constituintes, a exemplo do deputado Silva Lisboa, que segundo Mamigonian,

argumentou em favor da concessão de cidadania aos libertos, sem restrições, e não só àqueles que obtivessem liberdade através de carta de alforria, mas também por sentença judicial ou por disposição da lei [..] Ele argumentava pela incorporação dos libertos africanos em termos de direitos cívicos. [...] Por "direitos cívicos" entendia os que davam "ao homem livre o jus a dizer - tenho uma pátria; pertenço à tal cidade ou vila; não sou sujeito à vontade de ninguém, mas só ao império da lei. ${ }^{65}$

Essa percepção de cidadania sustentada nos "direitos cívicos" é facilmente identificável na carta de Lúcio, a exemplo do fragmento: "[...] a todo o ente humano sendo facultado a residência neste Império, dela querem privar o suplicante inofensivo, que outra pátria não tem senão o mesmo Império" (grifos nossos). ${ }^{66}$ Fundamental na missiva, embora subliminar, é a ideia de equiparação entre liberdade e naturalização. Sobre o processo de naturalização, Mamigonian evidencia ter sido para o africano, no mínimo, falacioso, "pois o candidato devia ser maior de 21 anos, estar no gozo de seus direitos como súdito estrangeiro, demonstrar ser possuidor de bens de raiz, ter parte em estabelecimento industrial ou exercer profissão útil, entre outros critérios".67 No entanto, a proposta apresentada pelo deputado Silva Lisboa considerava equiparar a emancipação e

64 APEB, Seção Colonial/Provincial, Correspondências do Consulado Inglês, Maço 1193. Período: 1872-1879.

65 MAMIGONIAN. "O direito dos libertos africanos no Brasil oitocentista", p. 190.

66 APEB, Seção Colonial/Provincial, Correspondências do Consulado Inglês, Maço 1193. Período: 1872-1879.

67 MAMIGONIAN. "O direito dos libertos africanos no Brasil oitocentista", p. 196. 
a naturalização, "e assim estender a cidadania a todos os alforriados no Brasil, independente do local de nascimento". ${ }^{68}$

A estrutura argumentativa e a narrativa presentes na carta transparecem um sentido de "cidadania" que ultrapassa o silêncio e as limitações da Constituição de 1824. Toda a linha de pensamento foi articulada de forma a reforçar a ideia de pertencimento daquele africano ao Império brasileiro. Os fios condutores foram: a chegada como escravo; a exploração de sua força de trabalho, cuja juventude e velhice aumentaram a fortuna pública; a compra da alforria; a obediência às leis divinas e humanas; e, por fim, a dádiva de ser progenitor de um cidadão brasileiro.

Homem temente a Deus, cumpridor das leis divinas e humanas, probo, trabalhador, inofensivo e pai de família, são argumentos usados para distanciar dele qualquer associação à natureza "perversa" do africano, amplamente disseminada naquele período. Esta análise não diminui em nada a importância que esses fatores tiveram na vida de Lúcio José, ao contrário, a carta mostra o quanto aqueles símbolos foram fundamentais para sua sobrevivência no Brasil.

Após a leitura da carta, o cônsul John Morgan escreveu uma comunicação ao presidente da província baiana, o barão de São Lourenço, solicitando-lhe que desembaraçasse o africano liberto. Tudo foi feito e encaminhado com rapidez. A resolução da contenda demoraria mais dois dias, considerando-se que o presidente da província esperou receber primeiro o relatório mensal das ocorrências policiais, enviado no dia 14 de abril pelo chefe de polícia local. ${ }^{69}$ No dia seguinte, por meio de outra comunicação, o presidente da província baiana permitiu a permanência de Lúcio José na Bahia.

Infelizmente, os livros de saída de passageiros do porto de Salvador e os registros de passaporte dos anos de 1871 e 1872 não resistiram à ação do tempo, de modo que ficamos sem saber quando ele pôde, finalmente, retornar a sua casa. Por outro lado, ao buscar informações sobre africanos que circularam entre Salvador e Lagos nas décadas de 1860 e 1880, localizamos Lúcio José circulando mais uma vez nos dois lados do Atlântico. Em janeiro de 1874, ele e a esposa, Benedita Rosa, vieram da Corte para Salvador no vapor nacional Rio Grande. Em 27 de setembro de 1883, consta um pedido de passaporte em seu nome com destino à costa da África. Dias depois, em 5 de outubro, seguiu viagem no patacho Rápido. ${ }^{70}$

Lúcio José retornou naquela embarcação em 21 de julho de 1884, seguindo viagem para o Rio de Janeiro apenas em 5 de agosto de 1884. Nos livros da polícia do porto da cidade do Rio de Janeiro, foi encontrado o registro em seu nome retornando da África. No documento consta que, em 8 de novembro de 1885, chegou à Corte no navio Senegal. ${ }^{11}$ Provavelmente essa embarcação pode ter feito escala em Salvador, tendo em vista que, naquele momento, a Cidade da Bahia era um porto importante de comunicação entre o Brasil e a costa ocidental do continente africano.

\section{Considerações finais}

Lúcio José Maria de Souza completou dez anos como liberto em 1871. Contudo, a simples posse da carta de alforria não lhe garantiu liberdade plena. Por meio

68 MAMIGONIAN. "O direito dos libertos africanos no Brasil oitocentista", p. 184.

69 APEB, Seção Colonial / Provincial. Correspondências do Presidente da Província, Maço 2966, 1871.

70 APEB, Livros de Saída de Passageiros, volumes 53, 54 e 55. Período: 1877-1890.

71 Agradeço a Lisa Castillo que, gentilmente, compartilhou estas informações comigo. 
da abordagem micro-histórica, constatamos que viver no gozo de sua liberdade, analogamente ao ocorrido com Lúcio José, foi uma tarefa difícil para milhares de africanos libertos residentes no Brasil oitocentista. Por outro lado, a redução na escala de observação, procedimento comum nesse tipo de abordagem, evidenciou as estratégias daquele africano liberto, cuja vida foi definida e reformulada a partir das experiências vividas antes, durante e após a escravidão.

Ao conquistarem a alforria, por compra ou doação, os africanos libertos enfrentariam inúmeras restrições em função de sua condição de apátridas. A omissão constitucional sobre a cidadania dos africanos libertos, articulada às legislações nacionais, provinciais e municipais, transformaram-nos em alvo constante de suspeição. A urgência de manter a ordem das relações escravistas, controlar a mão de obra e restringir a circulação dos libertos, em particular os africanos, estimulou a criação de leis, decretos, e posturas, a exemplo do Art. 70 do Código de Processo do Império, que determinava que os escravos mesmo acompanhados pelo senhor - e os libertos só poderiam viajar portando passaportes; ou a Lei n. ${ }^{\circ}$, de 10 de maio de 1935, que proibia a posse de bens de raiz, autorizava a deportação, controlava os espaços de trabalho e moradia dos africanos libertos. Houve ainda a cobrança de impostos daqueles que atuavam no mercado de rua, como o imposto no valor de 20 mil réis cobrado em 1856 dos africanos que mercadejavam pelas ruas. As pesadas taxações eram utilizadas com o intuito de estimular a saída "voluntária" dos africanos libertos da cidade para o campo ou mesmo retornarem ao continente africano.

A circulação de libertos africanos entre Rio de Janeiro, Salvador e Lagos foi o espaço geográfico no qual Lúcio José esteve presente. Iniciada na década de 1830 , as viagens de retornados, ex-escravos e descendentes foram constantes ao longo do século XIX. As décadas de 1860-1880 marcaram a intensidade desse fluxo, estimulado tanto pelo comércio entre Brasil e África, quanto pela repressão policial, além do intercâmbio cultural-religioso. O impedimento de Lúcio José e dos dezesseis africanos libertos do Paraguassu evidenciaram o (re)uso da lei de 7 de novembro de 1831 e, sobretudo, a ressignificação do passaporte inglês, concedido pelas autoridades inglesas aos retornados. Tanto a história de Lúcio José quanto o episódio dos dezesseis africanos libertos do Paraguassu destacaram a forte atuação do cônsul John Morgan em defesa dos interesses britânicos.

Ao recorrer à assistência do diplomata inglês, Lúcio José reafirmou sua identidade de africano liberto, mina, casado, pai e padrinho, trabalhador e inofensivo, "que outra pátria não tinha senão o mesmo Império, onde parte no cativeiro, parte no gozo de sua liberdade, envelheceu, aumentando com o produto do seu trabalho a fortuna pública". ${ }^{22}$ Para Lúcio José, a liberdade significa a manutenção da estabilidade familiar e preservação dos laços sociais, econômicos e culturais construídos no Rio de Janeiro.

Recebido em 27/07/2016

Aprovado em 06/01/2017 
